ISSN: 1858-4837; E-ISSN: 2598-019X

Volume 16, Nomor 2 (2021),

https://jurnal.uns.ac.id/region

DOI: 10.20961/region.v16i2.29728

\title{
Analisis kesesuaian koridor Jalan Gatot Subroto dan Jalan Dr. Radjiman sebagai pusat pelayanan perdagangan dan jasa Subosukowonosraten
}

\author{
Compatibility Analysis of Street Corridor of Jalan Gatot Subroto and Jalan Dr. \\ Radjiman as the Center of Trade and Service in Subosukowonosraten
}

\author{
S N Noorani ${ }^{1}$, Kusumastuti ${ }^{1}$, dan Soedwiwahjono ${ }^{1}$ \\ ${ }^{1}$ Program Studi Perencanaan Wilayah dan Kota, Fakultas Teknik, Universitas Sebelas \\ Maret
}

Corresponding author's email: shafanisrina4@gmail.com

\begin{abstract}
Abstrak. Pusat pelayanan memiliki fungsi untuk melayani wilayah hinterlandnya. Menurut RTRW Kota Surakarta Tahun 2011-2031, salahsatu pusat pelayanan perdagangan dan jasa terletak di Koridor Jalan Gatot Subroto dan Jalan Dr. Radjiman. Berdasarkan observasi lapangan, koridor ini merupakan pusat perbelanjaan yang sudah ada sejak lama sebelum munculnya pusat perbelanjaan modern di Kota Surakarta. Namun, masih terdapat permasalahan yang berkaitan dengan fungsinya sebagai pusat pelayanan. Permasalahan tersebut berupa daya tarik serta fasilitas pendukung yang kurang memadai. Penelitian ini akan membahas tentang kesesuaian koridor penelitian terhadap kebutuhan konsumen berdasarkan pada segmentasi pasar yaitu masyarakat menengah-bawah. Peneliti menggunakan data primer berupa observasi lapangan dan wawancara serta data sekunder berupa peraturan dan dokumen pemerintah. Teknik analisis yang digunakan adalah analisis skoring. Dalam mengetahui kesesuaiannya, terdapat 2 konsep yang digunakan sebagai variabel penelitian. Konsep tersebut adalah threshold dan range. Hasil dari penelitian ini menunjukan bahwa koridor penelitian memiliki beberapa permasalahan serta potensi yang dapat dikembangkan. Permasalahan tersebut berkaitan dengan daya tarik yang berdampak pada luas jangkauan pelayanan. Dilain pihak, potensi yang dimiliki berupa daya dukung lokasi dan threshold yang sudah memadai.
\end{abstract}

Kata Kunci: Kegiatan Perdagangan dan Jasa; Pusat Pelayanan; Segmentasi Pasar

Received: May 02, 2019; Accepted: September 26, 2019; Available online: July 15, 2021

Copyright $\odot$ 2021, REGION: Jurnal Pembangunan Wilayah dan Perencanaan Partisipatif 


\begin{abstract}
The service centre has a function to serve its hinterland area. According to the Surakarta City Spatial Plan for 2011-2031, one of the main trades and service centres is located in Gatot Subroto Street and Dr. Radjiman Street Corridor. Based on field observations, this corridor is a shopping centre that has existed since long before the emergence of modern shopping centres in Surakarta. However, there are problems relating its function as a service centre. The problem is in the form of attractiveness and inadequate supporting facilities. This study will discuss the suitability of the research corridor to the consumers' needs based on market segmentation, namely the lower middle class. Researchers used primary data in the form of field observations and interviews and secondary data in the form of government regulations and documents. The analysis technique used scoring analysis. In examining its suitability, there are two concepts used as research variables. The concept is threshold and range. The results of this study indicate that the research corridor has several problems and potential that can be developed. These problems are related to attractiveness that has an impact on the broad range of services. Meanwhile, the potential is in the form of an adequate location and threshold capacity.
\end{abstract}

Keywords: Market Segmentation; Service Centre; Trade and Service Activities

\title{
1. Pendahuluan
}

Setiap wilayah memiliki kondisi serta potensi yang berbeda-beda. Wilayah yang berperan sebagai pusat pelayanan memiliki fungsi untuk melayani wilayah hinterland-nya. Faktor agar wilayah hinterland terlayani, maka pusat pelayanan harus memiliki daya tarik. Daya tarik tersebut mampu menghilangkan unsur ruang yang sifatnya "mengganggu" yaitu jarak [1]. Jarak menjadi pertimbangan seseorang untuk melakukan perjalanan dari suatu lokasi menuju lokasi lain. Sehingga, dalam mendukung fungsi pusat pelayanan dibutuhkan lokasi yang dapat diakses dengan mudah oleh wilayah pelayanan. Selain aksesibilitas, dalam merencanakan pusat pelayanan perdagangan dan jasa perlu untuk mengidentifikasi kebutuhan konsumen. Hal ini berfungsi agar pelayanan mampu sesuai dengan apa yang diinginkan oleh konsumen.

Pada RTRW Kota Surakarta Tahun 2011-2031, Kota Surakarta didukung oleh potensi ekonomi yang sangat tinggi, yaitu di bidang perdagangan dan jasa [2]. Salah satu kegiatan perdagangan dan jasa yang menjadi pusat di Kota Surakarta terletak di koridor Jalan Gatot Subroto dan Jalan Dr. Radjiman. Koridor ini berperan sebagai pusat pelayanan kegiatan perdagangan dan jasa. Berdasarkan pengamatan peneliti, skala pelayanannya telah mencapai tingkat regional yaitu Subosukowonosraten. Pengunjung yang datang berasal dari pinggiran Kota Surakarta dengan jarak yang masih bisa dicapai dengan sepeda motor. Berdasarkan bentuk bangunannya, koridor penelitian merupakan pusat perdagangan dan jasa berupa shopping street. Shopping street merupakan kegiatan perdagangan dan jasa yang terdiri dari jalan utama, jalan pedestrian dan barisan pertokoan. Pada perkembangannya, koridor penelitian memiliki 2 anchor utama, yaitu Pasar Klewer dan Pasar Singosaren. Anchor memberikan daya tarik bagi pengunjung, sehingga menambah daya tarik untuk pertokoan kecil di sekitarnya [3]. 
Koridor penelitian memiliki kekuatan pasar karena terletak pada jantung Kota Surakarta. Untuk saat ini, koridor Jalan Gatot Subroto dan Jalan Dr. Radjiman telah didukung oleh sistem jaringan prasarana dan transportasi, antara lain adanya pengembangan jalan kolektor yaitu Jalan Dr. Radjiman serta pengembangan sistem prasarana angkutan umum (BST dan Feeder) [2]. Walaupun begitu, koridor masih memiliki permasalahan. Permasalahan tersebut antara lain berkaitan dengan daya tarik kawasan. Saat ini, daya tarik kawasan terbilang masih kurang. Koridor penelitian hanya berperan secara fungsional, yaitu untuk melayani kebutuhan pengunjung. Artinya, pengunjung yang datang ke wilayah penelitian memiliki urgensi untuk membeli barang saja. Sedangkan apabila melihat dari gaya hidup yang dimiliki oleh masyarakat menengah-bawah, mereka melakukan kegiatan belanja sekaligus mencari rekreasi dengan harga murah [4].

Permasalahan lain berupa fasilitas yang ada di kawasan. Untuk menunjang fungsi sebagai pusat pelayanan, seharusnya kawasan memiliki fasilitas pelayanan yang baik. Disebabkan oleh keterbatasan lahan, area koridor tidak memiliki parkir khusus selain on street. Di samping keterbatasan lahan, aktivitas lalu lintas di koridor Jalan Gatot Subroto dan Jalan Dr. Radjiman juga memiliki arus yang padat sehingga dampak yang ditimbulkan adalah kemacetan. Di sisi lain, aksesibilitas jalur penghubung berupa pedestrian juga terganggu akibat dari padatnya aktivitas kawasan yang memicu tumbuhnya sektor informal, yaitu PKL. Berdasarkan permasalahan tersebut, penelitian ini akan membahas tentang kesesuaian dari koridor penelitian terhadap kebutuhan konsumen berdasarkan segmentasi pasar, yaitu masyarakat menengah-bawah. Ketika suatu pusat mampu memaksimalkan kualitas pelayanan pada kelas konsumen yang dituju, maka secara otomatis perkembangan ekonomi suatu wilayah akan meningkat. Maka, diharapkan kajian ini dapat menjadi masukan dalam membuat arah pembangunan dan pengoptimalan peran kawasan sebagai pusat pelayanan.

\section{Metode}

Pendekatan yang digunakan pada penelitian ini adalah pendekatan deduktif dengan jenis penelitian kuantitatif. Teori yang digunakan pada penelitian ini berupa teori pusat pelayanan perdagangan dan jasa yang diterapkan pada koridor Jalan Gatot Subroto dan Jalan Dr. Radjiman, kemudian dilakukan pengukuran terkait kesesuaiannya. Pengukuran kesesuaian dihitung melalui setiap parameter variabel yang dibagi dalam 3 skala, yaitu sesuai, kurang sesuai dan tidak sesuai. Setelah perhitungan kuantitatif telah dilakukan, selanjutnya dilakukan penjelasan deskriptif terkait interpretasi dari nilai tingkat kesesuaian. Adapun variabel yang digunakan dalam penelitian ini dapat dilihat pada Tabel 1. 
Tabel 1. Variabel penelitian $[1,3,5-8]$.

\begin{tabular}{|c|c|c|c|c|}
\hline \multirow{2}{*}{\multicolumn{2}{|c|}{ Variabel Penelitian }} & \multirow{3}{*}{$\begin{array}{c}\text { Sub Variabel } \\
\text { Jarak }\end{array}$} & \multicolumn{2}{|l|}{ Kesesuaian } \\
\hline & & & Kecocokan & Ukuran Kemampuan \\
\hline \multirow[t]{7}{*}{ Range } & \multirow[t]{2}{*}{$\begin{array}{l}\text { Aksesibilitas } \\
\text { yang baik }\end{array}$} & & $\begin{array}{l}\text { Jarak tempuh masyarakat menuju } \\
\text { pusat pelayanan dekat }\end{array}$ & $\begin{array}{l}\text { - Sesuai } \\
\text { - Kurang sesuai } \\
\text { - Tidak sesuai }\end{array}$ \\
\hline & & Waktu & $\begin{array}{l}\text { Waktu tempuh masyarakat menuju } \\
\text { pusat pelayanan singkat }\end{array}$ & $\begin{array}{l}\text { - Sesuai } \\
\text { - Kurang sesuai } \\
\text { - Tidak sesuai }\end{array}$ \\
\hline & $\begin{array}{l}\text { Persebaran } \\
\text { kelompok } \\
\text { komoditi yang } \\
\text { memusat }\end{array}$ & - & $\begin{array}{l}\text { Pola persebaran toko membentuk } \\
\text { kelompok berdasarkan kesamaan } \\
\text { jenis barang/jasa yang ditawarkan }\end{array}$ & $\begin{array}{l}\text { - Sesuai } \\
\text { - Kurang sesuai } \\
\text { - Tidak sesuai }\end{array}$ \\
\hline & \multirow[t]{2}{*}{$\begin{array}{l}\text { Karakteristik } \\
\text { barang/jasa yang } \\
\text { ditawarkan }\end{array}$} & Harga & $\begin{array}{l}\text { Harga murah dengan kualitas barang } \\
\text { baik }\end{array}$ & $\begin{array}{l}\text { - Sesuai } \\
\text { - Kurang sesuai } \\
\text { - Tidak sesuai }\end{array}$ \\
\hline & & $\begin{array}{l}\text { Keanekaragaman } \\
\text { barang }\end{array}$ & $\begin{array}{l}\text { - Menyediakan produk baru } \\
\text { - Kalam jangka waktu tertentu } \\
\text { - Keberagaman desain produk } \\
\text { - Keberagaman variasi produk } \\
\text { - }\end{array}$ & $\begin{array}{l}\text { - Sesuai } \\
\text { - Kurang sesuai } \\
\text { - Tidak sesuai }\end{array}$ \\
\hline & \multirow[t]{2}{*}{$\begin{array}{l}\text { Terlayani fasilitas } \\
\text { dengan baik }\end{array}$} & Sarana & $\begin{array}{c}\text { Memiliki sarana dengan kelengkapan, } \\
\text { kapasitas yang memadai dan kualitas } \\
\text { yang baik }\end{array}$ & $\begin{array}{l}\text { - Sesuai } \\
\text { - Kurang sesuai } \\
\text { - Tidak sesuai }\end{array}$ \\
\hline & & Prasarana & $\begin{array}{c}\text { Memiliki prasarana dengan } \\
\text { kelengkapan, kapasitas yang memadai } \\
\text { dan kualitas yang baik }\end{array}$ & $\begin{array}{l}\text { - Sesuai } \\
\text { - Kurang sesuai } \\
\text { - Tidak sesuai }\end{array}$ \\
\hline \multirow[t]{2}{*}{ Threshold } & \multirow{2}{*}{$\begin{array}{c}\text { Konsentrasi } \\
\text { penduduk sesuai } \\
\text { dengan target } \\
\text { market }\end{array}$} & $\begin{array}{l}\text { Jumlah pembeli } \\
\text { potensial }\end{array}$ & $\begin{array}{l}\text { Jumlah pembeli potensial memenuhi } \\
\text { standar skala pelayanan }\end{array}$ & $\begin{array}{l}\text { - Sesuai } \\
\text { - Kurang sesuai } \\
\text { - Tidak sesuai }\end{array}$ \\
\hline & & $\begin{array}{l}\text { Distribusi kepadatan } \\
\text { penduduk }\end{array}$ & $\begin{array}{l}\text { Memiliki kepadatan penduduk tinggi } \\
\text { di sekitar lokasi pusat pelayanan }\end{array}$ & $\begin{array}{l}\text { - Sesuai } \\
\text { - Kurang sesuai } \\
\text { - Tidak sesuai }\end{array}$ \\
\hline
\end{tabular}

Dalam mengukur variabel, teknik pengumpulan data pada penelitian ini dibagi berdasarkan jenis data, yaitu data sekunder dan data primer. Data primer didapatkan melalui observasi dan kuesioner, sedangkan data sekunder melalui studi dokumen. Setelah mendapatkan data yang dibutuhkan berdasarkan variabel penelitian, selanjutnya dilakukan analisis. Teknik analisis yang digunakan adalah analisis skoring. Analisis skoring bertujuan untuk mengetahui tingkat kesesuaian melalui perhitungan kuantitatif. Penilaian setiap variabel dilakukan dengan cara memberi skor pada masing-masing variabel maupun sub variabel dengan skor 3 untuk kategori sesuai, skor 2 untuk kategori kurang sesuai dan skor 1 untuk kategori tidak sesuai. 
Hasil akhir dari analisis berupa jumlah skor kesesuaian pada tiap variabel dengan penentuan interval yang ditunjukan dalam Tabel 2 sebagai berikut.

Tabel 2. Ketentuan skor kesesuaian masing-masing variabel.

\begin{tabular}{|c|c|c|c|c|c|c|c|}
\hline \multirow[b]{2}{*}{ No } & \multirow[b]{2}{*}{ Variabel } & \multirow[b]{2}{*}{ Sub Variabel } & \multicolumn{3}{|c|}{ Skor } & \multirow[b]{2}{*}{$\begin{array}{c}\text { Skor } \\
\text { Maksimal }\end{array}$} & \multirow[b]{2}{*}{$\begin{array}{c}\text { Skor } \\
\text { Minimal }\end{array}$} \\
\hline & & & Sesuai & $\begin{array}{l}\text { Kurang } \\
\text { Sesuai }\end{array}$ & $\begin{array}{l}\text { Tidak } \\
\text { Sesuai }\end{array}$ & & \\
\hline \multirow[t]{2}{*}{1} & Aksesibilitas yang baik & Jarak & 3 & 2 & 1 & 3 & 1 \\
\hline & & Waktu & 3 & 2 & 1 & 3 & 1 \\
\hline 2 & $\begin{array}{c}\text { Persebaran kelompok } \\
\text { komoditi yang } \\
\text { memusat }\end{array}$ & - & 3 & 2 & 1 & 3 & 1 \\
\hline \multirow[t]{2}{*}{3} & Karakteristik & Harga & 3 & 2 & 1 & 3 & 1 \\
\hline & $\begin{array}{c}\text { barang/jasa yang } \\
\text { ditawarkan }\end{array}$ & $\begin{array}{c}\text { Keanekaragaman } \\
\text { barang }\end{array}$ & 3 & 2 & 1 & 3 & 1 \\
\hline \multirow[t]{6}{*}{4} & $\begin{array}{l}\text { Terlayani fasilitas } \\
\text { dengan baik }\end{array}$ & $\begin{array}{l}\text { Ketersediaan } \\
\text { Sarana }\end{array}$ & 3 & 2 & 1 & 3 & 1 \\
\hline & & Kapasitas Sarana & 3 & 2 & 1 & 3 & 1 \\
\hline & & Kualitas Sarana & 3 & 2 & 1 & 3 & 1 \\
\hline & & $\begin{array}{l}\text { Ketersediaan } \\
\text { Prasarana }\end{array}$ & 3 & 2 & 1 & 3 & 1 \\
\hline & & $\begin{array}{l}\text { Kapasitas } \\
\text { Prasarana }\end{array}$ & 3 & 2 & 1 & 3 & 1 \\
\hline & & Kualitas Prasarana & 3 & 2 & 1 & 3 & 1 \\
\hline \multirow[t]{2}{*}{5} & $\begin{array}{l}\text { Konsentrasi penduduk } \\
\text { dalam pemilihan lokasi }\end{array}$ & $\begin{array}{c}\text { Jumlah pembeli } \\
\text { potensial }\end{array}$ & 3 & 2 & 1 & 3 & 1 \\
\hline & $\begin{array}{c}\text { pusat pelayanan } \\
\text { perdagangan dan jasa }\end{array}$ & $\begin{array}{c}\text { Distribusi kepadatan } \\
\text { penduduk }\end{array}$ & 3 & 2 & 1 & 3 & 1 \\
\hline
\end{tabular}

Sehingga apabila diklasifikasikan, tingkat kesesuaian pusat pelayanan dengan fungsi kegiatan perdagangan dan jasa dapat dilihat pada Tabel 3 sebagai berikut.

Tabel 3. Klasifikasi kesesuaian.

\begin{tabular}{cc}
\hline Skala Kesesuaian & Klasifikasi Kesesuaian \\
\hline $30,34-39$ & Sesuai \\
$21,67-30,33$ & Kurang Sesuai \\
$13-21,66$ & Tidak Sesuai \\
\hline
\end{tabular}

\section{Hasil penelitian dan pembahasan}

\subsection{Range}

\subsubsection{Aksesibilitas yang baik}

3.1.1.1 Jarak. Dalam mengukur sub variabel jarak, peneliti menggunakan data asal-tujuan pengunjung pada wilayah penelitian. Didapatkan hasil bahwa pengunjung terjauh yang datang ke wilayah penelitian menempuh jarak $30 \mathrm{~km}$, dan pengunjung dengan jarak terdekat adalah $2 \mathrm{~km}$. Peta asal-tujuan dapat dilihat pada Gambar 2. Adapun dalam kompilasi data, peneliti 
mengelompokkan opini masyarakat tentang jauh tidaknya jarak yang mereka tempuh berdasarkan grafik pada Gambar 1 di bawah ini.

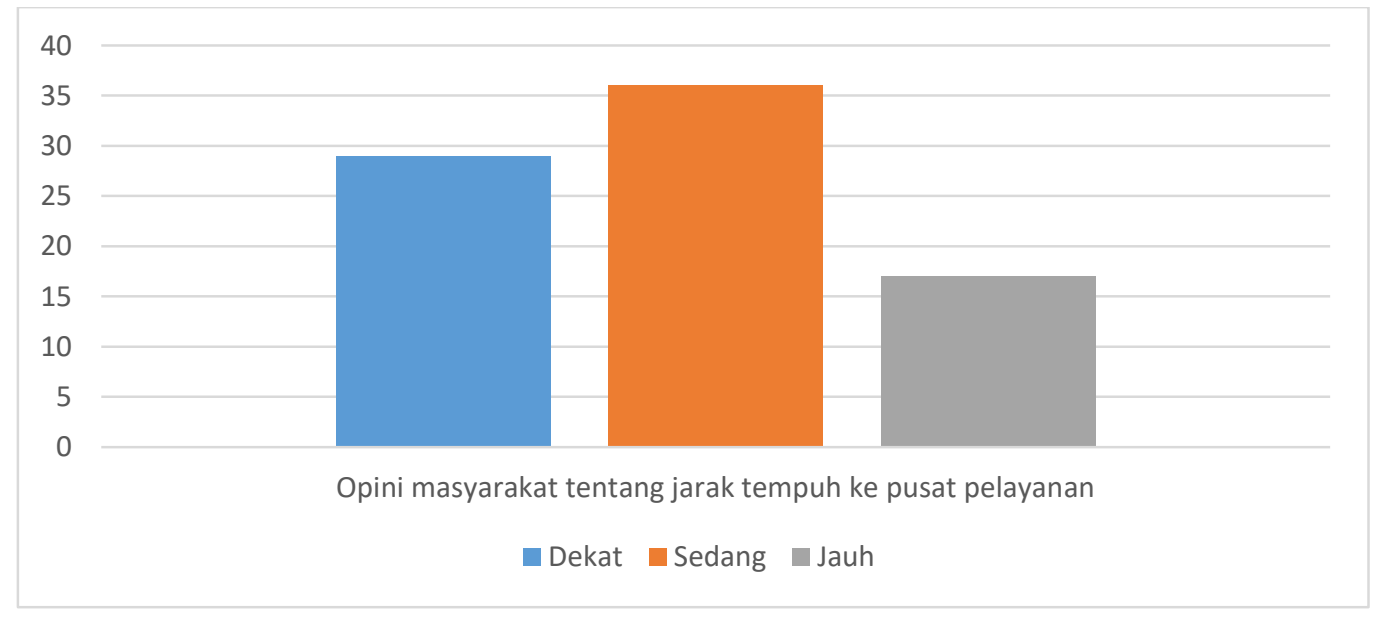

Gambar 1. Grafik opini masyarakat tentang jarak tempuh.

Berdasarkan data asal-tujuan, maka dapat juga digambarkan catchment area pada wilayah penelitian. Primary area yang menjadi area dimana mayoritas konsumen berasal memiliki area jangkauan $15 \mathrm{~km}$ (masyarakat yang menempuh jarak dekat-sedang). Sedangkan secondary area berasal dari konsumen dengan area jangkauan $30 \mathrm{~km}$ (masyarakat yang menempuh jarak sedang-jauh). Peta catchment area dapat dilihat pada Gambar 3.

Berdasarkan hasil analisis, dapat ditarik kesimpulan bahwa mayoritas pengunjung menempuh jarak yang sedang untuk mencapai pusat pelayanan. Jarak yang sedang berkisar antara 6,5 km - $13 \mathrm{~km}$. Hal ini kurang sesuai dengan kebutuhan konsumen koridor penelitian. Konsumen membutuhkan aksesibilitas yang baik menuju pusat pelayanan, sehingga jarak tempuhnya dekat. Skoring sub variabel jarak dapat dilihat pada Tabel 4.

Tabel 4. Skoring parameter jarak.

\begin{tabular}{cc}
\hline Hasil Penelitian & Skor Parameter \\
\hline $\begin{array}{c}\text { Jarak tempuh masyarakat menuju } \\
\text { pusat pelayanan } 6,5-13 \mathrm{~km}\end{array}$ & $\mathbf{2}$ \\
\hline
\end{tabular}




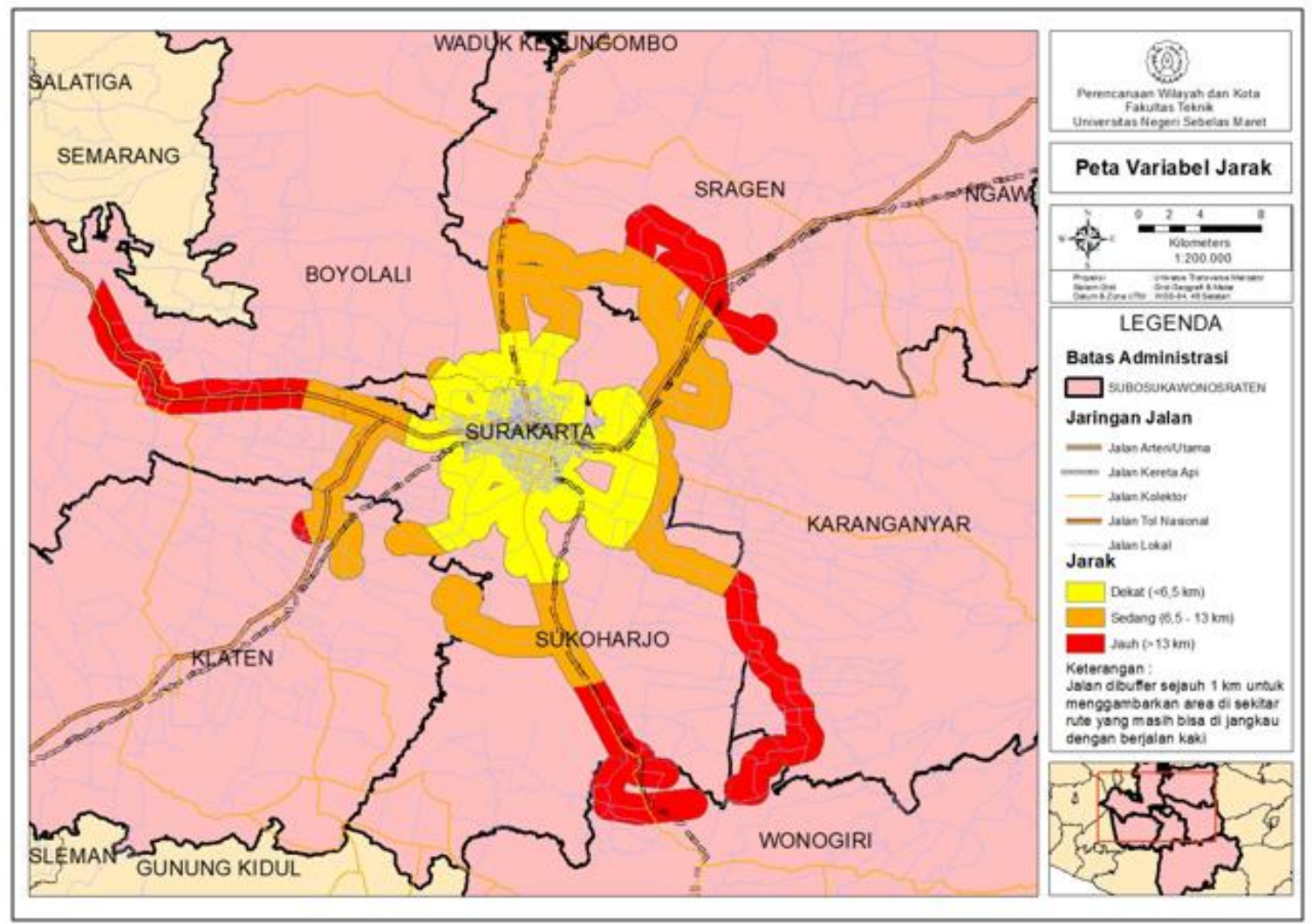

Gambar 2. Peta variabel jarak.

Dari hasil analisis, mengindikasikan bahwa masyarakat masih mengalami hambatan dalam melakukan perjalanan menuju pusat. Hambatan tersebut salah satunya dapat disebabkan oleh kemacetan pada jaringan jalan penghubung Kota Surakarta dengan kabupaten lainnya.

3.1.1.2 Waktu. Waktu merupakan ukuran dari lama perjalanan yang dibutuhkan masyarakat untuk mencapai pusat pelayanan. Dari hasil kuesioner didapat hasil bahwa $50 \%$ pengunjung menempuh waktu yang sedang dari tempat bermukim menuju pusat pelayanan. Rentang waktu yang sedang adalah antara 10-20 menit seperti Tabel 5. Pengunjung ini biasanya berasal dari dalam Kota Surakarta dan urban fringe area. Sedangkan menurut $46 \%$ pengunjung, mereka menempuh waktu yang lama yaitu > 20 menit dari tempat bermukim. Dari hasil analisis, dapat ditarik kesimpulan bahwa waktu tempuh menuju pusat pelayanan adalah kurang sesuai karena termasuk ke dalam kategori sedang. Konsumen membutuhkan lokasi pusat pelayanan dengan aksesibilitas yang baik, sehingga waktu tempuhnya singkat. Dari hasil analisis mengindikasikan bahwa masih adanya hambatan lalu lintas dalam perjalanan pengunjung menuju koridor penelitian. Berikut merupakan peta variabel waktu tempuh menuju pusat pelayanan yang dapat dilihat pada Gambar 4. 


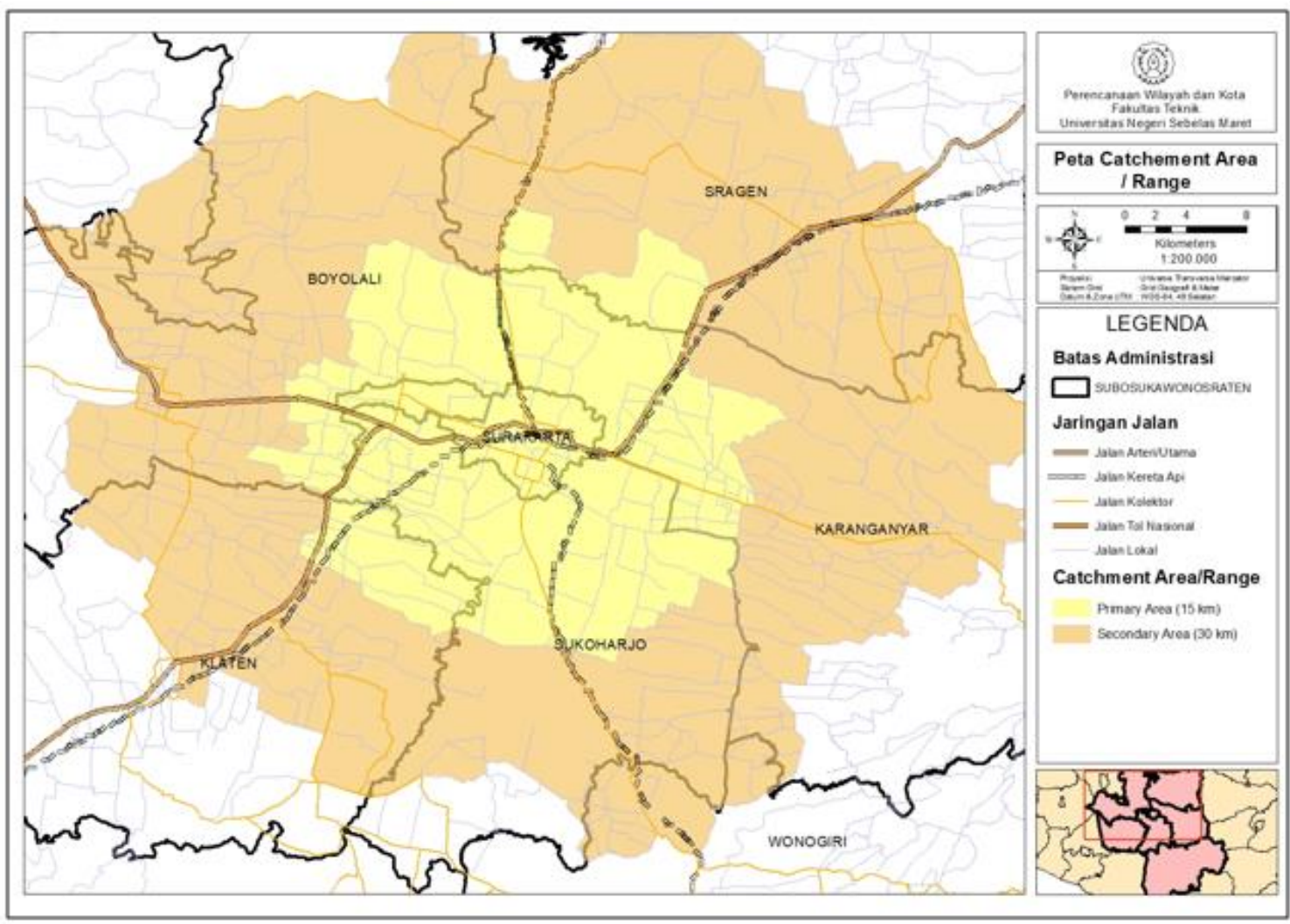

Gambar 3. Peta catchment area.

Tabel 5. Skoring parameter waktu tempuh ke pusat pelayanan.

\begin{tabular}{cc}
\hline Hasil Penelitian & Skor Parameter \\
\hline Waktu tempuh masyarakat menuju pusat pelayanan 10-20 menit & $\mathbf{2}$ \\
\hline
\end{tabular}

Dapat ditarik kesimpulan bahwa waktu tempuh menuju pusat pelayanan adalah kurang sesuai karena termasuk ke dalam kategori sedang. Hal ini disebabkan oleh kondisi lalu lintas pada jaringan jalan yang kurang mendukung, seperti kemacetan atau rekayasa lalu lintas yang kurang sesuai.

3.1.2 Persebaran kelompok komoditi yang memusat. Variabel ini diukur dengan cara mengetahui pola persebaran kegiatan perdagangan dan jasa berdasarkan kesamaan jenis barang/jasa yang ditawarkan. Untuk mengetahui pola persebaran setiap kelompok komoditi, maka dilakukan perhitungan berdasarkan rumus tetangga terdekat. Berikut hasil perhitungan dari rumus tetangga terdekat dapat dilihat pada Tabel 6. 


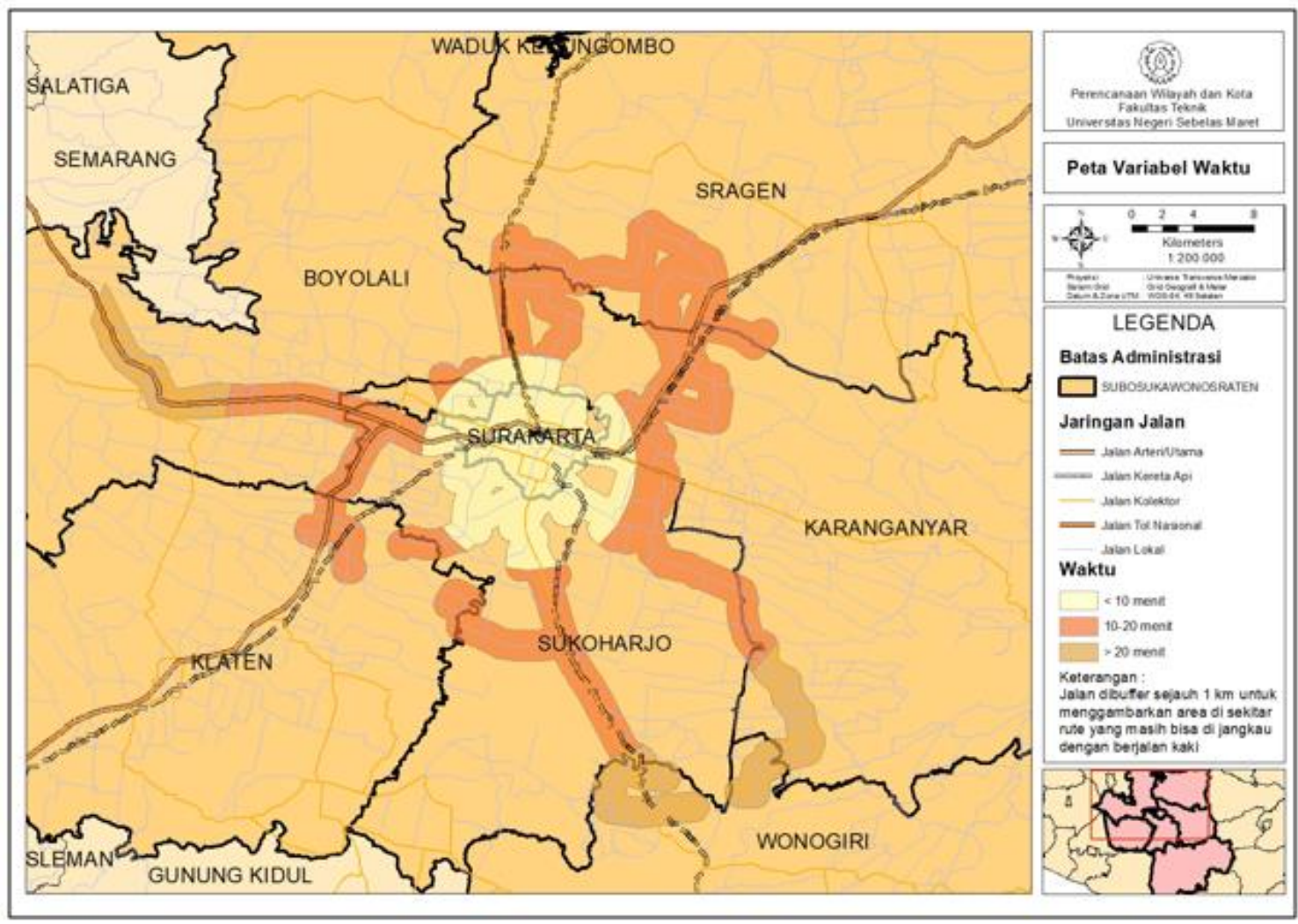

Gambar 4. Peta variabel waktu tempuh ke pusat pelayanan.

Tabel 6. Perhitungan variabel pola persebaran toko menurut kelompok komoditi.

\begin{tabular}{clcccc}
\hline No & Kelompok Komoditi & $\boldsymbol{I} \boldsymbol{u}(\mathbf{m})$ & $\boldsymbol{I h}(\mathbf{m})$ & $\mathbf{T}(\mathbf{m})$ & Pola persebaran \\
\hline 1 & Bahan baku pakaian & 25 & 12 & 2,08 & Pola tersebar merata \\
2 & Elektronik & 46 & 24 & 1,91 & Pola tersebar merata \\
3 & Fashion store & 23,7 & 14 & 1,69 & Pola tersebar merata \\
4 & Hotel & & & Hanya ada 1 & \\
5 & Kesehatan & 23,5 & 11,21 & 2,09 & Pola tersebar merata \\
6 & Keuangan & 33 & 15,83 & 2,08 & Pola tersebar merata \\
7 & Minimarket & & Hanya ada 1 & \\
8 & Otomotif & & Hanya ada 1 & \\
9 & Peralatan ibadah & 21 & 10,12 & 2,07 & Pola tersebar merata \\
10 & Peralatan musik & 27 & 12,6 & 2,14 & Pola tersebar merata \\
11 & Perhiasan & 13,05 & 10,05 & 1,29 & Pola tersebar tidak merata \\
12 & Perlengkapan rumah tangga & 24,3 & 13,53 & 1,79 & Pola tersebar merata \\
13 & Salon & 27 & 14,34 & 1,88 & Pola tersebar merata \\
14 & Tempat makan/resto & 25,33 & 12,7 & 1,99 & Pola tersebar merata \\
15 & Toko alat tulis & & & Hanya ada 1 & \\
16 & Toko mainan & 15 & 10,55 & 1,42 & Pola tersebar merata \\
17 & Toko makanan hewan & & & Hanya ada 1 & \\
18 & Toko sepeda & & & & \\
\hline
\end{tabular}

Dari perhitungan tabel di atas, dapat ditarik kesimpulan bahwa pola persebaran kegiatan perdagangan dan jasa pada wilayah penelitian membentuk pola tersebar merata. Kondisi 
seperti ini kurang sesuai terhadap kebutuhan konsumen. Berdasarkan pola kelompok komoditas yang tersebar, maka konsumen akan kesulitan dalam membandingkan barang. Padahal berdasarkan perilaku konsumen, konsumen cenderung menginginkan kemudahan dalam mencari barang. Hal tersebut yang akan mengurangi daya tarik pengunjung.

Kegiatan perdagangan dan jasa pada wilayah penelitian cenderung berjalan masing-masing dan tidak terintegrasi. Padahal, dengan bentuk ruang shopping street seharusnya memberikan akses penghubung antara satu kegiatan dengan kegiatan lain. Berdasarkan uraian terkait konsentrasi komoditas skor parameter dari variabel ini dapat dilihat pada Tabel 7 sebagai berikut.

Tabel 7. Skoring parameter persebaran kelompok komoditi.

\begin{tabular}{cc}
\hline Hasil Penelitian & Skor Parameter \\
\hline Nilai $T=1,41-2,1491$ (Pola tersebar merata) & 1 \\
\hline
\end{tabular}

Perkembangan toko pada koridor penelitian tidak dapat diatur keberadaannya. Hal ini disebabkan karena bangunan pada koridor penelitian dimiliki oleh pribadi, sehingga pemerintah tidak dapat melakukan zonasi kegiatan. Oleh karena itu, upaya yang dapat dilakukan untuk mengatasi permasalahan tersebut salah satunya adalah menawarkan transportasi lokal dalam kawasan untuk mengakomodasi pergerakan pengunjung. Transportasi (feeder/pengumpan) yang biasa digunakan berupa becak. Penyediaan transportasi lokal bertujuan agar pengunjung dapat menghemat waktu dalam berpindah lokasi. Transportasi lokal memberikan aksesibilitas tambahan bagi pengunjung, serta menambahkan nilai rekreasi dalam berbelanja.

\subsubsection{Karakteristik barang dan jasa yang ditawarkan}

3.1.3.1 Harga. Sub variabel ini diukur dengan cara membandingkan harga barang/jasa pada wilayah penelitian dengan pusat perbelanjaan lain di Kota Surakarta. Bagi masyarakat menengah-bawah, harga sangat menentukan keputusan dalam membeli barang. Perbandingan harga dilakukan dengan membandingkan Solo Paragon Mall dan PGS (Pusat Grosir Solo) terhadap koridor Jalan Gatot Subroto dan Jalan Dr. Radjiman. Kedua pusat perbelanjaan ini dinilai mewakili karakteristik pusat perbelanjaan di Kota Surakarta.

Dari hasil observasi didapatkan perbedaan harga yang cukup jauh antara harga barang pada Solo Paragon Mall serta barang pada wilayah penelitian. Misalnya aksesoris, Solo Paragon Mall menawarkan harga Rp 50.000 dan pada barang dengan kualitas yang sama wilayah penelitian menawarkan harga Rp 45.000. Selanjutnya pada komoditi pakaian bayi, Solo Paragon Mall menawarkan harga Rp 170.000 sedangkan toko pakaian bayi pada wilayah penelitian menawarkan harga Rp 90.000. Pada komoditi ini perbedaan harga mencapai hampir 2 kali lipat. Sedangkan untuk pakaian dewasa, Solo Paragon Mall menawarkan harga Rp 300.000 dan disisi lain toko baju pada wilayah penelitian menawarkan harga Rp 150.000 . 
Perbandingan harga kemudian dilakukan kepada barang di Pusat Grosir Solo yang menawarkan produk fashion seperti pakaian. Dari hasil observasi pada jenis dan kualitas barang yang sama, Pusat Grosir Solo menawarkan harga yang mirip dengan barang pada wilayah penelitian. Pusat Grosir Solo menawarkan harga Rp 110.000, sedangkan toko pakaian pada wilayah penelitian menawarkan harga Rp 111.000. Kedua barang ini memiliki harga yang relatif sama. Perbedaannya adalah dalam proses pemasaran, Pusat Grosir Solo menawarkan harga grosir sehingga harga bisa menjadi lebih murah.

Dari uraian perbandingan harga di atas, dapat ditarik kesimpulan bahwa harga barang yang ditawarkan oleh pelaku usaha pada wilayah penelitian termasuk dalam kategori murah dengan kualitas yang memadai seperti yang tertera pada Tabel 8. Hal ini sesuai dengan kebutuhan masyarakat menengah-bawah yang menjadi konsumen dari koridor penelitian.

Tabel 8. Skoring parameter harga.

\begin{tabular}{cc}
\hline Hasil Penelitian & Skor Parameter \\
\hline Harga barang murah dengan kualitas baik & $\mathbf{3}$ \\
\hline
\end{tabular}

3.1.3.2 Keanekaragaman barang. Sub variabel keanekaragaman barang diukur melalui 4 komponen. Komponen tersebut berupa ketersediaan produk baru, keberagaman desain produk (berbagai macam desain dalam satu produk), keberagaman variasi produk (berbagai macam jenis barang/jasa yang ditawarkan) dan keberagaman merk. Secara umum, wilayah penelitian telah menawarkan berbagai macam jenis komoditi yang sifatnya saling komplementer. Karakteristik dari masing-masing toko memiliki produk dengan variasi merk serta desain yang beragam. Dengan begitu, wilayah penelitian memiliki daya tarik yang bagus dari segi keanekaragaman barang yang ditawarkan. Hal ini sesuai dengan kebutuhan konsumen koridor penelitian yang menginginkan pusat pelayanan mampu menawarkan keanekaragaman barang. Maka, skor parameter dari sub variabel keanekaragaman barang dapat dilihat pada Tabel 9 sebagai berikut.

Tabel 9. Skoring parameter sub variabel keanekaragaman barang.

\begin{tabular}{cc}
\hline Hasil Penelitian & Skor Parameter \\
\hline $\begin{array}{c}\text { Terdapat 4 komponen indikator keanekaragaman } \\
\text { barang pada wilayah penelitian }\end{array}$ & $\mathbf{3}$ \\
\hline
\end{tabular}

3.1.4 Terlayani fasilitas dengan baik. Fungsi dari pusat pelayanan perdagangan dan jasa adalah untuk melayani wilayah di sekitarnya. Agar fungsi pusat pelayanan dapat berjalan optimal, maka dibutuhkan sarana prasarana yang sesuai berdasarkan ketersediaan, kapasitas dan kualitasnya.

3.1.4.1 Sarana. Dari hasil survey terkait ketersediaan sarana, terdapat 4 komponen sarana yang sudah tersedia berupa parkir umum, bank/atm, pos polisi dan tempat ibadah. Adapun sarana yang belum tersedia adalah pos pemadam kebakaran. Berdasarkan penelitian yang dilakukan oleh Fauzi [9] terkait efektivitas komponen manajemen risiko bencana kebakaran di Kota Surakarta, kinerja dari pos pemadam kebakaran yang melayani koridor penelitian (pos 
gading) hanya melayani $38 \%$ dari jangkauan pelayanannya. Akibatnya, koridor penelitian tidak mampu terlayani dengan baik. Skoring parameter dari ketersediaan sarana dapat dilihat pada Tabel 10 sebagai berikut.

Tabel 10. Skoring parameter ketersediaan sarana.

\begin{tabular}{cc}
\hline Hasil Penelitian & Skor Parameter \\
\hline $\begin{array}{c}\text { Tersedia 3-4 komponen sarana pusat pelayanan } \\
\text { perdagangan dan jasa }\end{array}$ & 2 \\
\hline
\end{tabular}

Berkaitan dengan kapasitas sarana, terdapat sarana parkir dan sarana pos polisi yang kapasitasnya belum memadai. Hal ini disebabkan karena keterbatasan lahan serta bangunan pada koridor penelitian. Keterbatasan lahan parkir pada koridor penelitian dapat diatasi apabila parkir off street dapat dimanfaatkan secara optimal. Parkir off street yang memungkinkan adalah dengan memanfaatkan gedung parkir di Pasar Klewer dan Pasar Singosaren. Berikut Tabel 11 merupakan skoring parameter kapasitas sarana.

Tabel 11. Skoring parameter kapasitas sarana.

\begin{tabular}{cc}
\hline Hasil Penelitian & Skor Parameter \\
\hline Nilai kapasitas sarana yang memadai $33,4 \%-66,6 \%$ & 2 \\
\hline
\end{tabular}

Sedangkan apabila dilihat dari kualitasnya, sarana pendukung kegiatan pada wilayah penelitian memiliki kualitas yang baik, kecuali sarana parkir. Parkir umum memiliki permukaan jalan yang buruk sehingga berpengaruh pada penataan parkir. Berikut merupakan skoring parameter kualitas sarana wilayah penelitian dapat dilihat pada Tabel 12.

Tabel 12. Skoring indikator kualitas sarana.

\begin{tabular}{cc}
\hline Hasil Penelitian & Skor \\
\hline Nilai kualitas sarana yang memadai $33,4 \%-66,6 \%$ & 2 \\
\hline
\end{tabular}

3.1.3.2 Prasarana. Dari hasil survey terkait ketersediaan prasarana didapatkan hasil bahwa seluruh komponen prasarana pendukung pada wilayah penelitian tersedia. Maka, skoring dari parameter ketersediaan prasarana dapat dilihat pada Tabel 13.

Tabel 13. Skoring parameter ketersediaan prasarana.

\begin{tabular}{cc}
\hline Hasil Penelitian & Skor Parameter \\
\hline $\begin{array}{c}\text { Tersedianya } 7 \text { komponen prasarna pusat pelayanan } \\
\text { perdagangan dan jasa }\end{array}$ & 3 \\
\hline
\end{tabular}

Selanjutnya, berkaitan dengan kapasitas prasarana, masih terdapat kapasitas prasarana yang belum memadai. Prasarana tersebut berupa jaringan jalan (lebar jalan kurang), jaringan air bersih (tidak menyediakan kran umum serta hidran), jaringan persampahan (kapasitas TPS overload) dan jaringan transportasi lokal (jumlah halte kurang). Oleh karena itu, dapat ditarik kesimpulan bahwa hanya terdapat $43 \%$ prasarana wilayah penelitian yang sudah memadai. Skoring parameter kapasitas prasarana dapat dilihat pada Tabel 14 sebagai berikut. 
Tabel 14. Skoring indikator kapasitas prasarana.

\begin{tabular}{cc}
\hline Hasil Penelitian & Skor \\
\hline Nilai kapasitas prasarana yang memadai $33,4 \%-66,6 \%$ & 2 \\
\hline
\end{tabular}

Dari segi kualitas, masih terdapat prasarana yang kualitasnya buruk. Prasarana tersebut berupa jaringan jalan, jaringan persampahan dan jaringan transportasi lokal. Kualitas prasarana jalan yang buruk disebabkan arus kendaraan stop and go sehingga menyebabkan permukaan jalan bergelombang. Sedangkan pada jaringan persampahan, kualitas buruk disebabkan karena tidak adanya sampah khusus yang disediakan bagi pengunjung. Skoring parameter kualitas prasarana wilayah penelitian dapat dilihat pada Tabel 15 sebagai berikut.

Tabel 15. Skoring indikator kualitas prasarana.

\begin{tabular}{cc}
\hline Hasil Penelitian & Skor \\
\hline Nilai kualitas prasarana yang memadai $33,4 \%-66,6 \%$ & 2 \\
\hline
\end{tabular}

\subsection{Threshold}

3.2.1 Jumlah pembeli potensial. Menurut data BPS Provinsi Jawa Tengah, pengeluaran perkapita dibagi menjadi 3 kelompok. Kelompok pertama, yaitu penduduk dengan pengeluaran $\mathrm{Rp}$ 150.000-Rp 499.000/bulan. Kelompok kedua, yaitu penduduk dengan pengeluaran Rp 500.000-Rp 999.000/bulan. Dan kelompok ketiga, yaitu penduduk dengan pengeluaran $>$ Rp 1.000.000. Apabila dikaitkan dengan pembeli potensial pada wilayah penelitian, maka kelompok pengeluaran penduduknya adalah kelompok yang kedua. Oleh karena itu, jumlah pembeli potensial dari wilayah pelayanan dapat dilihat pada Tabel 16.

Tabel 16. Data jumlah penduduk menengah-bawah Subosukowonosraten.

\begin{tabular}{|c|c|c|c|c|c|c|}
\hline No & Kabupaten & $\begin{array}{c}\text { Kelompok } \\
\text { Pengeluaran } \\
\text { (Rupiah/perkapita } \\
\text { /bulan) }\end{array}$ & $\begin{array}{l}\text { Persentase } \\
\text { Jumlah } \\
\text { Pembeli } \\
\text { Potensial (\%) }\end{array}$ & $\begin{array}{l}\text { Jumlah } \\
\text { Penduduk } \\
\text { Menengah- } \\
\text { Bawah }\end{array}$ & $\begin{array}{c}\text { Persentase Jumlah } \\
\text { Pembeli Potensial } \\
\text { Berdasarkan Asal } \\
\text { Pengunjung (\%) }\end{array}$ & $\begin{array}{l}\text { Jumlah } \\
\text { Pembeli } \\
\text { Potensial }\end{array}$ \\
\hline 1 & Surakarta & \multirow{7}{*}{$\begin{array}{c}500.000- \\
999.000\end{array}$} & 35 & 180.000 & 35 & 63.000 \\
\hline 2 & Sukoharjo & & 44 & 383.414 & 11 & 42.175 \\
\hline 3 & Boyolali & & 32 & 310.184 & 11 & 34.000 \\
\hline 4 & Klaten & & 48 & 558.344 & 11 & 61.000 \\
\hline 5 & Karanganyar & & 46 & 397.449 & 11 & 44.000 \\
\hline 6 & Sragen & & 57 & 502.791 & 11 & 55.200 \\
\hline 7 & Wonogiri & & 59 & 561.665 & 11 & 61.000 \\
\hline \multicolumn{6}{|c|}{ Jumlah Pembeli Potensial } & 360.000 \\
\hline
\end{tabular}

Dari hasil perhitungan tabel di atas, maka jumlah pembeli potensial sudah mampu berkonstribusi dalam mendukung kegiatan di koridor penelitian. Sehingga, tabel skoring indikator jumlah penduduk pendukung potensi pasar dapat dilihat pada Tabel 17. 
Tabel 17. Skoring jumlah pembeli potensial.

\begin{tabular}{cc}
\hline Hasil Penelitian & Skor Indikator \\
\hline Jumlah Penduduk 320.000-480.000 jiwa & 3 \\
\hline
\end{tabular}

3.2.2 Distribusi kepadatan penduduk. Langkah pertama untuk mengukur sub variabel ini adalah dengan cara mengidentifikasi tingkat kepadatan penduduk pada wilayah pelayanan. Tingkat kepadatan penduduk dibagi menjadi 3 kelas, yaitu rendah, sedang dan tinggi. Tingkat kepadatan rendah memiliki range 0-1893 jiwa/km2. Sedangkan tingkat kepadatan sedang memiliki range 1893-6696 jiwa/km2. Tingkat kepadatan tinggi memiliki range 6697-15941 jiwa/km2. Setelah menentukan tingkat kepadatan, selanjutnya dilakukan overlay antara peta kepadatan penduduk dengan peta jangkauan pelayanan wilayah penelitian (catchment area). Maka dapat terlihat apakah kepadatan penduduk berlokasi di dalam jangkauan pelayanan wilayah penelitian dengan peta yang dapat dilihat pada Gambar 5.

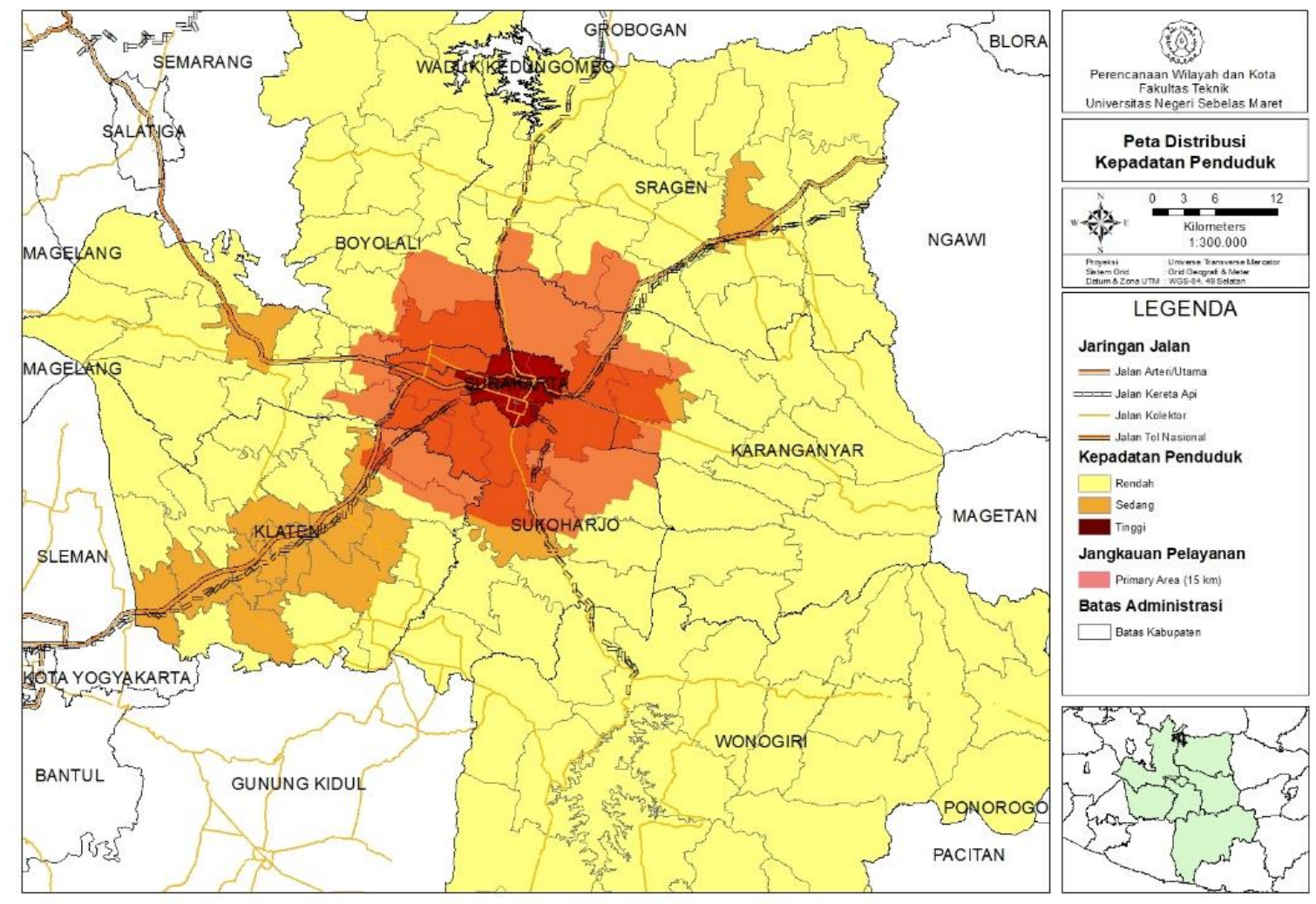

Gambar 5. Peta sub variabel distribusi kepadatan penduduk.

Berdasarkan peta di atas, wilayah penelitian termasuk ke dalam kelompok kepadatan penduduk tinggi. Oleh karena itu, kegiatan perdagangan dan jasa menempati lokasi yang sesuai sebagai pusat pelayanan. Dengan lokasi yang dekat dengan konsentrasi penduduk, maka diharapkan dapat menambahkan nilai aksesibilitas bagi pengunjung karena dekat. Di sisi lain, pelaku usaha mampu mendapatkan keuntungan dari penjualan apabila banyak penduduk 
yang menggunakan pelayanan. Berikut Tabel 18 merupakan skor parameter dari sub variabel lokasi kepadatan penduduk.

Tabel 18. Skoring parameter lokasi kepadatan penduduk.

\begin{tabular}{cc}
\hline Hasil Penelitian & Skor Parameter \\
\hline $\begin{array}{c}\text { Kepadatan penduduk tinggi disekitar pusat } \\
\text { perdagangan dan jasa }\end{array}$ & $\mathbf{3}$ \\
\hline
\end{tabular}

Hasil dari analisis skoring pada setiap komponen kesesuaian pusat pelayanan kemudian digabungkan menjadi 1 matriks dengan perhitungan sebagai berikut (lihat Tabel 19).

Tabel 19. Skoring kesesuaian masing-masing variabel.

\begin{tabular}{|c|c|c|c|c|c|}
\hline \multirow{2}{*}{ No } & \multirow{2}{*}{ Variabel } & \multirow{2}{*}{ Sub Variabel } & \multicolumn{3}{|c|}{ Skor } \\
\hline & & & Sesuai & Kurang Sesuai & Tidak Sesuai \\
\hline \multirow[t]{2}{*}{1} & Aksesibilitas yang baik & Jarak & - & 2 & - \\
\hline & & Waktu & - & 2 & - \\
\hline 2 & $\begin{array}{c}\text { Persebaran kelompok } \\
\text { komoiditi yang memusat }\end{array}$ & - & - & - & 1 \\
\hline \multirow[b]{2}{*}{3} & Karakteristik barang/jasa & Harga & 3 & - & - \\
\hline & yang ditawarkan & $\begin{array}{c}\text { Keanekaragaman } \\
\text { barang }\end{array}$ & 3 & - & - \\
\hline \multirow[t]{6}{*}{4} & Terlayani fasilitas dengan & Sarana & - & 2 & - \\
\hline & baik & & - & 2 & \\
\hline & & & - & 2 & - \\
\hline & & Prasarana & 3 & - & - \\
\hline & & & - & 2 & - \\
\hline & & & - & 2 & - \\
\hline \multirow[t]{3}{*}{5} & $\begin{array}{l}\text { Konsentrasi penduduk } \\
\text { sesuai dengan target }\end{array}$ & $\begin{array}{l}\text { Jumlah pembeli } \\
\text { potensial }\end{array}$ & 3 & - & - \\
\hline & market & $\begin{array}{l}\text { Distribusi kepadatan } \\
\text { penduduk }\end{array}$ & 3 & - & - \\
\hline & Total Skor & & & 29 & \\
\hline
\end{tabular}

Total skor parameter kesesuaian pusat pelayanan koridor Jalan Gatot Subroto dan Jalan Dr. Radjiman adalah 29. Kemudian untuk mengetahui tingkat kesesuaiannya dilakukan klasifikasi berdasarkan tabel berikut (lihat Tabel 20).

Tabel 20. Klasifikasi kesesuaian.

\begin{tabular}{cc}
\hline Skala Kesesuaian & Klasifikasi Kesesuaian \\
\hline $30,34-39$ & Sesuai \\
$21,67-30,33$ & Kurang Sesuai \\
$13-21,66$ & Tidak Sesuai \\
\hline
\end{tabular}

Menurut tabel klasifikasi kesesuaian, hasil analisis kesesuaian pusat pelayanan berada pada skala kesesuain 21,67 - 30,33. Artinya, koridor Jalan Gatot Subroto dan Jalan Dr. Radjiman memiliki tingkat kesesuaian sebagai pusat pelayanan dengan fungsi kegiatan perdagangan dan jasa yang kurang sesuai. 


\section{Kesimpulan}

Berdasarkan hasil analisis dan pembahasan, maka dapat ditarik kesimpulan bahwa koridor penelitian memiliki beberapa permasalahan dan potensi yang dapat dikembangkan. Sebagai pusat perbelanjaan "konvensional" di Kota Surakarta, koridor penelitian memiliki kekuatan yang membuatnya dapat bersaing dengan pusat perbelanjaan modern seperti mall. Kebertahanan kegiatan perdagangan dan jasa pada koridor penelitian didukung oleh lokasinya yang berada pada pusat Kota Surakarta. Kota Surakarta sendiri telah menjadi magnet kegiatan bagi kabupaten di sekitarnya. Oleh karena itu, koridor penelitian memiliki daya dukung berupa jumlah pembeli potensial yang memadai. Namun, potensi tersebut tidak didukung oleh daya tarik yang dimiliki oleh koridor penelitian. Hal inilah yang membuat kegiatan yang ada di koridor penelitian tidak berkembang.

Selain membutuhkan pusat pelayanan dengan lokasi yang strategis (dekat dengan pusat permukiman dan memiliki kemudahan aksesibilitas), masyarakat menengah-bawah juga membutuhkan kenyamanan belanja (konsentrasi komoditas dan fasilitas pendukung yang memadai) dan keanekaragaman barang (harga murah dan jenis barang yang beragam). Berdasarkan hasil analisis, komponen koridor penelitian yang belum sesuai dengan kebutuhan konsumen menengah-bawah adalah aksesibilitas, persebaran kelompok komoditi serta fasilitas pendukung. Perlu dilakukan peningkatan kualitas pelayanan pada komponen tersebut agar fungsi koridor sebagai pusat pelayanan dapat lebih optimal. Selain optimal, koridor penelitian juga mampu memiliki daya saing terhadap pusat perbelanjaan lainnya.

\section{Referensi}

[1] Tarigan R. Perencanaan Pembangunan Wilayah. Jakarta: PT. Bumi Aksara; 2005.

[2] Pemerintah Kota Surakarta. Peraturan Daerah Kota Surakarta Nomor 1 Tahun 2012 tentang Rencana tata Ruang Wilayah Kota Surakarta Tahun 2011-2031 2012.

[3] Gibbs RJ. Principles Of Urban Retail Planning And Development. Canada: John Wiley \& Sons, Inc.; 2012.

[4] Bäckström K. Shopping as leisure: An exploration of manifoldness and dynamics in consumers shopping experiences. J Retail Consum Serv 2011;18:200-9. https://doi.org/10.1016/j.jretconser.2010.09.009.

[5] Djojodipuro M. Teori Lokasi. Jakarta: Lembaga Penerbit Fakultas Ekonomi Universitas Indonesia; 1992.

[6] Wyckoff W. Central Place Theory and The Location of Services in Colorado in 1899. Soc Sci J 1989;26:383-98. https://doi.org/10.1016/0362-3319(89)90003-7.

[7] El-Adly MI. Shopping malls attractiveness: A segmentation approach. Int J Retail Distrib Manag 2007;35:936-50. https://doi.org/10.1108/09590550710828245.

[8] Foster B. Manajemen Ritel. Bandung: Penerbit Alfabeta; 2008.

[9] Fauzi M. Efektivitas Komponen Manajemen Risiko Bencana Kebakaran di Kota Surakarta. Universitas Sebelas Maret, 2019. 